\title{
Revisiting the Stereoscopic Archive as a Memory Recalling Device
}

\author{
Angélica Yaneth Piedrahita Delgado \\ Department of Arts. Universidad de Monterrey UDEM \\ Av. Morones Prieto 4500 PTE, San Pedro Garza Garcia, N.L. México, C.P. 66238 \\ angelica.piedrahita@udem.edu
}

\begin{abstract}
The article unfolds the process of Stereo Nostalgia and Telematic Rides Along the Caribbean, an artistic research project that analyses a stereoscopic 3D tour made by the American company Underwood \& Underwood in Colombia at the beginning of the 20th century. The project displays particular aspects of stereoscopy's visual experience on archival material, recalling the colonial memory of the place. Through video footage and recorded interviews, the project narrates the experience of exploring the places photographed, interacting with the current inhabitants to whom the archival images are introduced in 3D. When presenting the stereoscopic experience to the people from Barranquilla, memories about the urban development of the city, concerns about its heritage and nostalgia of a golden economic era are triggered. The exercise of unfolding the visual memory through a tactile like experience gained through the technique, engaged the viewers in a particular way of experiencing collective memory.
\end{abstract}

3D stereoscopy, expanded archives, colonial gaze, material culture, virtual tourism, visual memory.

\section{INTRODUCTION}

Immersive media comes from a legacy of precinematographic devices like the stereoscope, where the observer and the observed seem to occupy the same space-time. Oculus Rift, Vive and PlayStation VR, follow immersion archetypes of media history; involving the observer in such a way that it's own space-time is concealed as it is transported to the photographed space-time. The present work focuses on reviewing stereoscopy's cognitive and narrative potential on Caribbean history through the institutional view of the stereographic archive. Through out the paper, stereoscopy will be contemplated as an apparatus that points out ambiguous limits between the eye and the image, transposing not only images but also gazes and ideological perspectives. It will focus on the observation of the sites photographed more than a hundred years later, rethinking the site's memory by means of the spread out archive.

\section{VIRTUAL STEREO TOURS AND THE EYE}

Both virtual reality VR and augmented reality AR, transform the embodied experience of space and time by adding and juxtaposing images to our sensitive map. The eyes are trapped by images that cover the whole field of vision. In front of each eyeball, is placed a lens that brings a unique image closer and rounded allowing a sense of depth that transfigure distances and spatial references; deconstructing the image by its distance from the eye. Stereoscopy considers interocular distance to produce a conglomerate of near and distant surfaces that don't correspond to a proportional representation of space. It introduces the gaze into a borderless space, where each eye tries to converge with each other in corresponding points of two slightly displaced images. In this space produced by an optical converge, a pair of seemingly free eyes traverse spaces stopping, revisiting or omitting sections of the image. Immersion in stereoscopy points out relationships between the eyeballs, the camera, the gaze and the image. These relationships are framed in cultural contexts, power structures and forms of production as well as the subjective dimensions of the observer and the observed. In short, the technique transcends the primordial and inevitable identification of the eye of the spectator and the lens of the camera. For Jean-Louis Comolli (2010), eye and camera are related entities not equivalent, because, the technogenesis of optical devices shaped the current ways of seeing. For Comolli:

The eye is not in front of a camera, but in front of a device for the production of images that displace and at the same time legitimizes human vision. The hundreds of small machines of the nineteenth century intended for the reproduction of the image are part of the taxonomy of a large machine of representation in which societies 
have participated (2010 p.122) [...] The camera with the laws of perspective gave the monocular vision a primordial place displacing the human vision by pointing out its shortcomings (2010 p.124).

Exploring stereographs implies following points of convergence in pairs of images, it gives the viewer an apparent freedom to scan the image thoroughly, deploying complex asociations and revealing the observer attention. During the second half of the nineteenth century, stereophotography was a popular mean of representing the modern world. At the hand of this type of photographs, images of colonized territories circulated responding to a frenzy of travel diaries and visual expansions of the world. For the time, it seemed as if the whole world became visible and at the same time appropriable (Comolli 1980, p. 123). Pornography, tourism, war photojournalism and school education were some of the many areas in which stereoscopic images were produced with the interest of converging vision and cognition. Through the device, the eye acquired a certain spatial experience, where I have seen appeared equivalent to I know.

The stereoscope gives the eye the spatial sensation of a place or an object that is not present; consequently, since its appearance stereoscopic photography was marketed as substituent of the experience itself. For Jonathan Crary, in Techniques of the Observer,

\begin{abstract}
"the effect pursued by the stereoscope was not only of similarity, but of an apparent immediate tangibility" (2008, p.162),
\end{abstract}

which added another stimulus to the experience of observing photographs. Citing, Hermann Von Helmholtz, - German physicist promoters of the device-Crary states that, the real experience

\footnotetext{
"added nothing to the apperception obtained with stereoscopy at least from the relationship of form" (2008, p.164).
}

And later on, Kaja Silverman (2009), citing Crary, insist that the stereoscope's popularization accelerated the appearance of a referential crisis, manifesting the inability of the eyes to see what is in space and triggering questions about the perception of distance and its relation to the body. However, Von Helmholtz (1885) understood and tried to explain the differences between the visual sensation of reality and the one through stereo photography. He acutely explained Wheatstone's research in Recent Progress of Theory of Vision (1885) and agreed to recognize cognition by virtue of the stereoscope, stating that he himself experienced places never sawn before through the stereoscope understanding its deceptive nature. However, he as well as other physiologist neither could get rid of the sensation of that illusion nor report the phenomenon with his own worlds.

Von Helmholtz seemed to attest through scientific inquiry, that presentabilia, a concept akin to Edmund Husserl's phenomenological concept Gegenwärtigung translated as presentation and defined as perception, is a phenomenon by which the world is presented to us and we explore it through voluntary motion. In Facts of Perception (1878), Von Helmholtz asserted that it was only by the movements of the eye or the body that we could grasp an intuition of the form of an outer. In the quest of cognitive research he understood a self that is constantly limited by a circle of presentabiliaii, in which as the body (eyes or sensorimotor) moves, it actualizes its intuition of space as well as it's own bodily understanding within it. As Husserl, Helmholtz understand a body that is constituted as experienced, however for Husserl and the later phenomenologist as well as cognitive scientist aligned to phenomenology, the main focus of perception was the experiential attitude of sensing oneself in contact with another in time.

At the beginning of the 20th century, schoolbooks accompanied by stereoscopic images in the United States, apprized the benefits of teaching from stereo photographs as well as the need to study them critically and inquisitively. By 1885 the use of the technique convey to prove that retinal movement as well as touch, were akin to cognition. Experimental sciences of the nineteenth century welcomed an active and autonomous visual experience, related to sensory structural stimulus. Moreover, it was accepted the idea of imagination constructed according to the depth of sensed data, being very difficult to construct imagery to which there is nothing analogous in experience (Helmholtz, 1878). Nowadays, is been proved the technique's efficiency to navigate through simulations to harness training capabilities. On virtual or augmented reality, proprioception is recognized as the core of the experience: monitoring extremely fine movement has been accomplished through stereoscopic photography paired with photogrammetry, $360^{\circ}$ cameras and wireless devices above other technologies. Provocative examples of its use are: the OpsLab NASAiii project at the Jet Propulsion Laboratory in California; The Machine to Be Anotheriv an interdisciplinary group of artist located in Barcelona; and a clinical, interactive, exposure therapy tool from the University of Southern California called The Bravemindv. This later example, unfold cognitive and memory concerns regarding soldiers returning from battlegrounds in Afghanistan and Iraq with traumatic injuries. The Bravemind tool aims to expand, and extend clinical care methodologies in behavioral healthcare technology for the purpose of treating posttraumatic 
stress disorder PTSD. In that sense even though, simulation can't replace reality, there are some sensory cues that could be triggered through involuntary memory that could relocate sensory maps structured in our bodies.

The observation through the stereoscope requires first a gradual movement of convergence of the retina so the eye adapts to the distances of the image components. While observing with the apparatus, the eye reacts with small movements called saccades, in which the ciliary muscle moves constantly so the fovea can access specific points of focus. We constantly make these movements in our daily visual experience searching for visual intersections. Points that converge result on the illusion of depth, thus stereoscopic vision is related to the brain's ability to seek convergence. Discontinuity and non-convergence are tools of reflection on reality itself, discontinuous, incongruous and never complete. We are constantly looking for stories, stories, memories and images from which we can extract apparent continuities. Nowadays, the eye travels through a non-homogeneous space and follows the curves and angles of the image for an haptic experience, in which the surfaces are inspected in search of continuity. Each exploration of the image is different, the viewer give attention to different components of the image in each observation.

\section{STEREOSCOPY, MEMORY AND THE ARCHIVAL}

Roger Shattuck (2016) studies the work of Marcel Proust using various optical devices as a metaphor, to reflect on time, vision and perception. According to Shattuck, the optical depth of the stereoscope is for Proust the perfect analogy to describe the perception of the depth of time. The principle of stereoscopy in Proust's temporal metaphors takes into consideration two memories far enough apart from one another:

\footnotetext{
"We have only to select in our memory two pictures taken at different moments, close enough together however for them not to have altered in themselves -perceptibly, that is to sayand the difference between the two pictures is to measure the displacement that they have undergone in relation to us " (p.151).
}

Temporal depth is acquired by two close experiences in time that shape the complexity of the story in memory. In correspondence with the eye in stereoscopic experiences, the convergence movements of the memory allows an aesthetic experience that tries to relate the vertiginous uncertainty of the distances in which the memories are found; moments full of complexities and affection related to the photographic instant. For Ricour, Remembrance of Things Past confirms the dimensional character of time, the itinerary of the novel moves form the idea of a distance that separates of that of a distance that joins together (2010, p 269). As Shattuck, Ricoeur, sees stereoscopy as one of the hermeneutical keys to Remembrance. Following the lines of Proust at The Guarmantes Way, Ricoeur sees how the author declares that for the writer as well as for the painter is not a matter of technique but of vision, understanding vision as the act of reading signs, recognizing or even failing to recognize the signs in time (2010, p 265). A perceptive exercise in which identity (whatever that means in terms of self) is constantly reexamined through the signs presented to our eyes. The imagery and memory of an object in time is as different as the observer that saw it for the first time as the one that is remembering. Proust's examples of involuntary and eidetic memory are both an act of recognition oneself in front of what is remembered.

Stereoscopy became popular in the United States along with expansionist interests and a growing system of images of the world, which made it possible for middle class consumers to visit places that could not be visited so easily. It also gave the American student the privilege of being acquainted with ways of life and events around the world. Among many of the commercial photographs, the stereoscopic tours in particular were products that narrated stories of the world before radio, film and television. These sets of photographs took as a theme a profitable place and explored it with the help of photographs, maps and travel guides adding data and observations of the place. The images of the stereoscopic tours were also regrouped in much more extensive collections that promoted trips around the world through the telebinocular in which the images were organized by geographical indexes, agriculture, horticulture, ethnic groups, cultures, architecture or history, among other categories (Holmes, 1936).

The idea of representation of a distant space and the sense of tangibility of these representations contribute to a market of stereoscopic destinations that lead photographers to portray distant places, bringing these places before the eyes of the viewer. On the back of each stereophotography was commonly printed a description or name of the photographed place and additional information about it. The commercial success of stereoscopic tours was based on the immobility of their constumers as well as their desire to apprehend the world around. The stereoscope market was anchored in the immobility of many bodies and the expectance of turning experience into knowledge and power. Box Sets, or Collection Boxes were the first products released by Underwood \& Underwood and Keystone View Company in the United States, before the brand textbooks. Collection boxes were sets of images designed for 
wealthy families in which images were grouped by countries or continents. Latin America was widely photographed, and Colombia was photographed during a series of trips between 1896 and 1940.

The first recorded trip was made by the American photographer D. H. Ashton (Piedrahita, 1987). His voyage cover Barranquilla and its surroundings, at the time the city was recognized as the country's major maritime port. Ashton followed commercial guidelnes that ensured the publication of his photographs, maintaining patterns used tirelessly in other tours to please privileged families in North America and Europe. The media archeologist Erkki Huhtamo (2006) considers stereoscopy as the first social mass medium introduced in private spaces. For Huhtamo, this device was the first one placed in the privacy of the home, introducing consumer and production relations akin to radio and television (p. 99) with modern expansionist interests, integrated to a large production system of mass consumption.

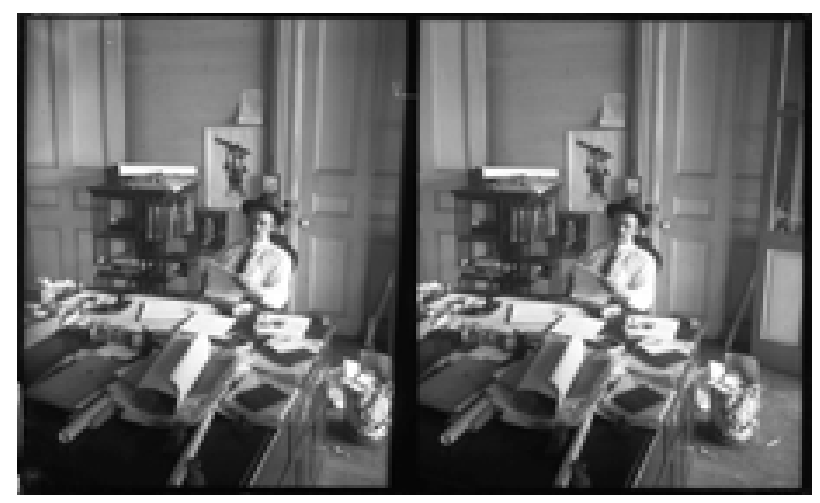

Figure 1: Man at desk, Panama. Keystone Mast Collection, UCR. OAC Identifier: 1996.0009.X89239

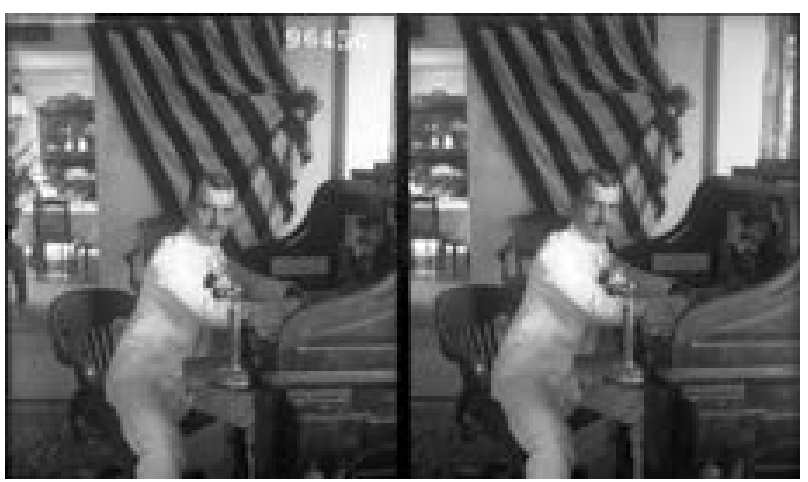

Figure 2: Man at his desk, Barranquilla. Keystone Mast Collection, UCR. OAC Identifier: 1996.0009.X96450

Men at deskvi (figures 1, 2, 3 and 4) and Wash dayvii (figures 5, 6 and 7) are recurring categories on tours to the Philippines, Peru, Cuba or Panama. The first one, portrays the scene of a modern man in front of his desk, from which we can not know a name or a profession. Notwithstanding stereophotographs of north american men on hs desks had their full name and profession in the front of the image. These unnamed subjects are part of a category that allows north americans to recognize familiar scenarios in other countries, representing the willingness of expanded enterprises in those countries. The second category analized here, is one in which scenes of laundry follow composition models from picturesque landscapes. These images portrayed women wearing and washing white clothes following a standarized composition found on travel lectures and accounts around the world, famous for exoticizing the so called desolated tropics through narrations, photographs and magic lantern slides.

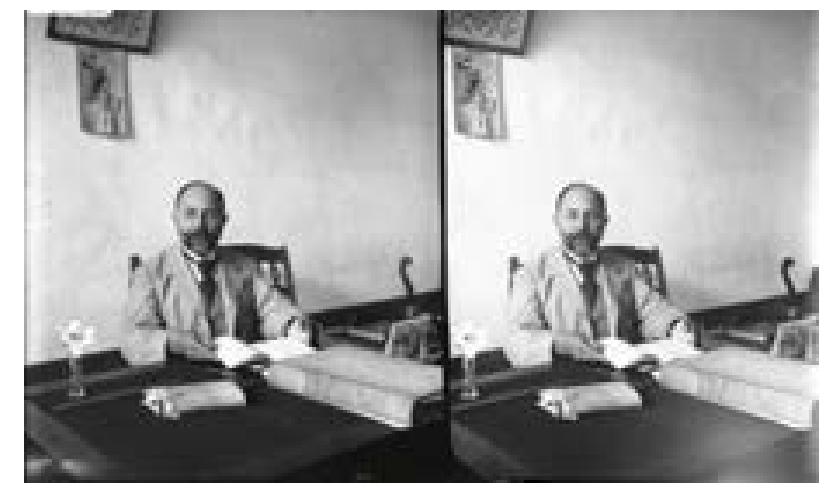

Figure 3: Man at his desk, Cuba. Keystone Mast Collection, UCR. OAC Identifier: 1996.0009.X46160

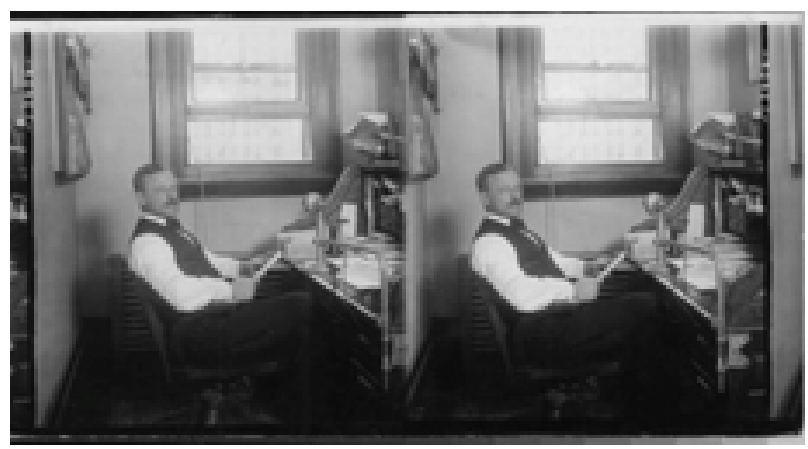

Figure 4: Mr. Jerome. District attorney at his desk, New York. Keystone Mast Collection, UCR. OAC Identifier: 1996.0009.WX13006.SS 


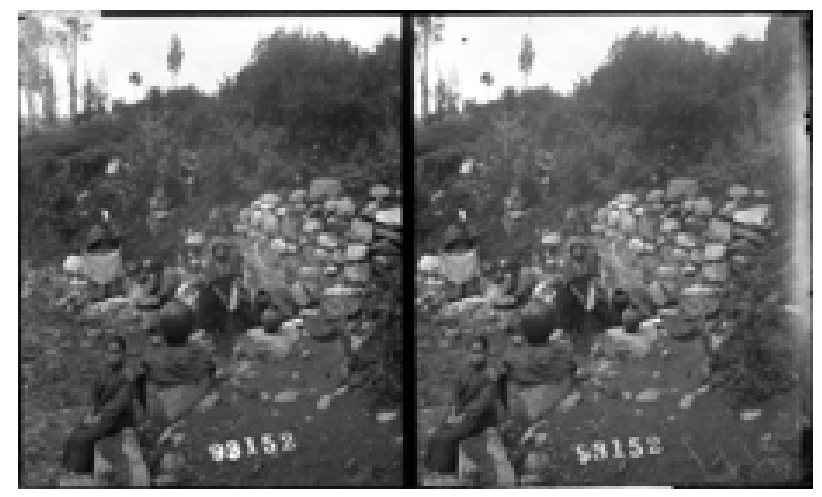

Figure 5: Wash Day. Cuzco. Perú. Keystone Mast Collection, UCR. OAC Identifier: 1996.0009.X93152

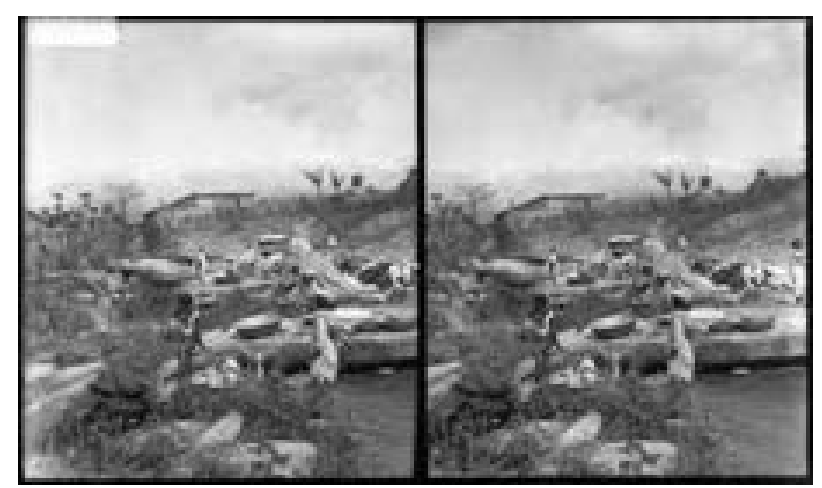

Figure 6: Wash Day. Cuba. Keystone Mast Collection, UCR. OAC Identifier: 1996.0009.X45938

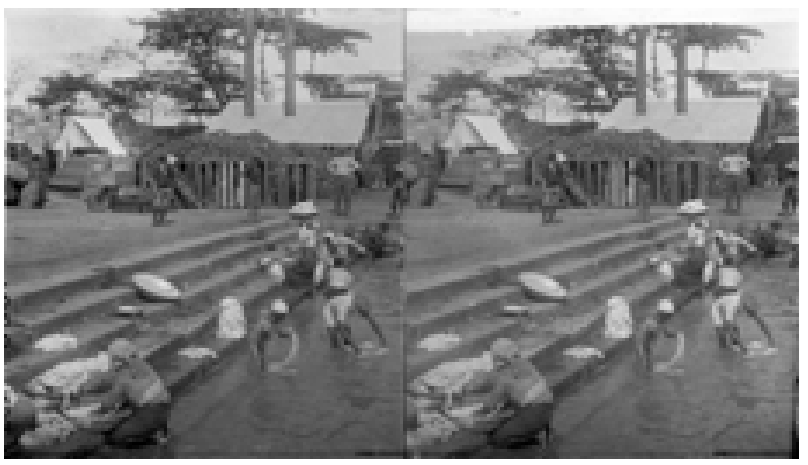

Figure 7: Washing Day on the Banks of the Pasig Manila. Keystone Mast Collection, UCR. OAC Identifier: 1996.0009.21300

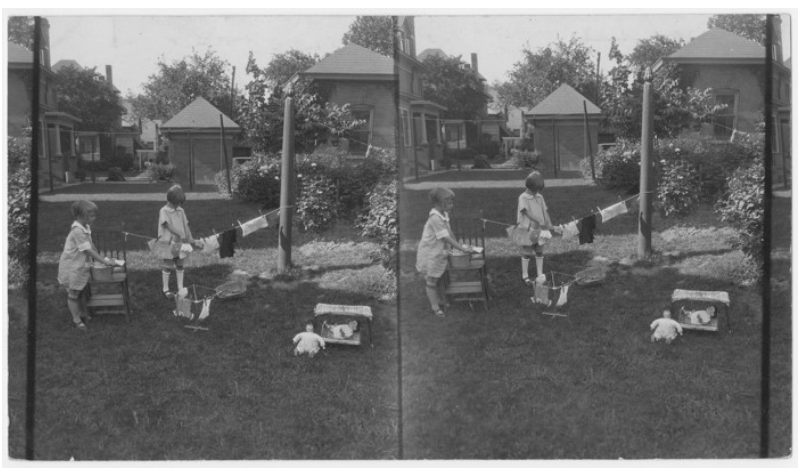

Figure 8: Wash Day. Pennsylvania. V. J. Stanton. Keystone Mast Collection, UCR. OAC Identifier: 1996.0009.21300

These images follow the aesthetic of native cleanliness in addition to stressing the godliness (good negro behaviour), 'the divine sanction of imperialism' (Thompson, 2007, p 70). 'These images conveys the native acquiescence to colonial instilled mores of gooming and higyne, despite their humble outdoors and tropical surroundings, [...] assuring prospective visitors that the tropic inhabitants were civilized' (ibid.). The subject would constitute a deep investigation in itself and exceeds the interests of the present work; However, it is important to list some of the subjects of interest to understand a little better the type of images that were reproduced. In Peru, Cuba, the Philippines and Colombia, the scenes take place in the open air, performed by older women in quite precarious situations, while in the american stereophotographs the scene portray little girls playing to washclothes (figure 8). In both cases, the photographs respond to general categories that follow colonial stereotypes, in spite of its distorted dominant position, they are considered an important part of the visual memory of the Colombian Caribbean (González, p 2004), and a detailed observation unfold historically unbalanced configurations of power in the city.

The gaze granted by these trips to Barranquilla at the threshold of the twentieth century is a commodified, massified gaze, obscured by the widespread western geopolitics a well as submerged in the visual codes of a colonial market. Box sets as luxury products followed the logic of world tourism and colonial dynamics. Presenting exchangable characteristics of the place, recognized exoticisms, representations of western imaginaries domesticated within a "universal" system of signs that the cosmopolitan visitor recognizes and communicates (D'Hauteserre 2004; Urry 1990). This recognition can lighten the visitor's journey through the place, and even in many cases enhances the desire to travel. For Urry (2002 [1990]), tourists are like pilgrims after the symbols of the place they visit. Those who travel with a cosmopolitan spirit celebrate and respect differences with the ease and pleasure of recognizing a place from apperception.

For Mike Crank (2004), tourism is not only an activity of consumption of places, but it is also a force that dynamically creates them. It spatialize social meanings, tracing a story about the territory using myths, dreams, and landmarks. By creating spaces and placing them on a map, places end up integrated into a global narration that reinforce novel routes and forget less notoriuos ones. The stereoscopic tours indicated places and topics to be observed, today, those places have been 
neglected by city administration and policy making, advocating for new projects increasingly modernized. Historical centers condense complex layers of urbanization, memories and displacements that continuously respond to its irremediable context. While, the dislocated peripheries follow a progressive advance away from the center, obeying global consumption trends visible in architecture and urban planning. During December 2016 and January 2017, as part of the analysis of these images, I made a tour following the spaces photographed by Ashton in downtown Barranquilla. At the beginning of my visit, I went after the traces of buildings and characters portrayed on the images I found. The information collected from the archive of the University of California were the Underwood \& Underwood archival is located, don't hold enough information from that specific tour. As a result, I decided to bring the stereophotographs to the eyes of historians and residents of Barranquilla in order to open up other Caribbean routes that escape the exotic images of national campaigns and commercial agendas that tend to sell natural exuberance, remote landscapes and beachfront resorts.

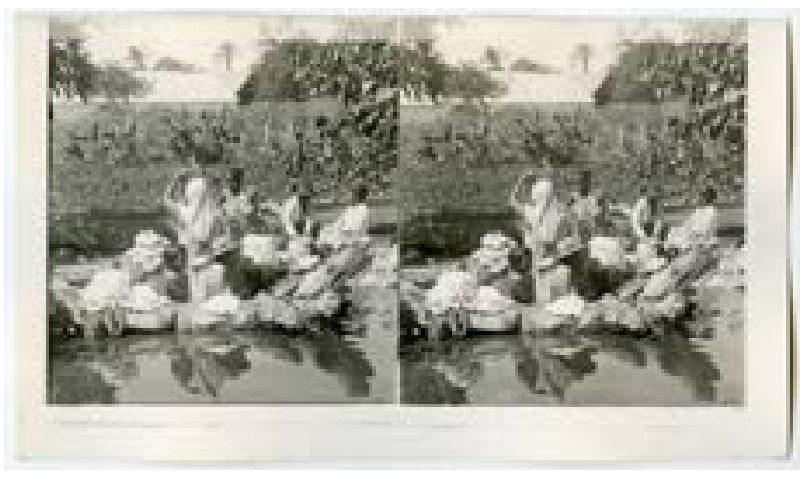

Figure 9: A Colombian Washing Day Along the Magdalena River Near Barranquilla, Colombia. Keystone Mast Collection, UCR. OAC Identifier:1996.0009.X11517

Bringing the stereoscopic space of Ashton's journey to bygone dwellers, historians as well as passerby caused different reactions according to the place from which each subject observed. Merchants, workers, inhabitants and passerby at the city center wondered the kinship of the device with the presumed novel virtual reality. For them, recognizing places on the stereophotographs seemed to resignified the surroundings. The story of a photographer sent by an American company to capture images of downtown Barranquilla and its surroundings, uncoupled the archival material from upper class collections and identified it with a global tourism symbol system exoticizing their past. This identification from tourism, added an exchange value to the space triggering romantic memories of an irreversible past. The archival material through the stereoscope allowed the convergence between a nostalgic past assumed proximate and diverse present contexts. The reaction towards the technique was strong in comparison with observing the images without the stereoscope. Many of the merchants immediately saw in the device the potential element necessary to persuade the eyes of the current administration to promote the recovery of the historical center as it is being done in other areas of the city. However, their biggest promise seemed to be the visit of tourists and the believe that the reactivation of the space will happened as local and foreign visitors start touring the downtown area.

Historians specialized in Barranquilla's history, from their specialist point of view, recognized many of the images as work tools. The historian's vision inquisitively explored the spaces of the image and reviewed information already acquired. With precision, these observers located the photographed places and realized the evident changes after a century. His narration was interspersed with data brought from books, photographs, family experiences and historical imagination (Ricoeur, 2010). At the church of San Nicolas, for example, the historian Adlai Stevenson assures that the photograph was taken around 1896 and not in 1913 date recorded by previous investigations. According to Stevenson's research and sources it's remodeling in 1897 changed the dissimilar structure of the towers noted in the archival image. After one or three minutes observing the image, almost every person expressed their findings, memories or acquired knowledge about Barranquilla's history. The experience with the device in most cases resulted in short anecdotes that resonated emotionally with the observer. The images brought about reflections on life in Barranquilla at the beginning of the 20th century, bad administrative decisions, informal trades, the founding of the city, local commerce and the displacement of the Mokanás -natives of the region-, among many other topics.

Compared with the producers intentions, the observations done by citizens of Barranquilla, lack of categories and classifications; their visual journey contain the surfaces of familiar images and memories. For Huhtamo (2006), observing through the stereoscope was far from being an individual experience; the archive images retrieved by the researcher reported meetings in which the stereoscope was part of group activities in visiting rooms. After the fieldwork in Barranquilla, I could conclude that the three-dimensional sensation stimulated the need to communicate the experience. Once experienced, people invited others to observe, indicating the way to use the device. The images that at some point were a marketable and generalizing products became detonators of collective memories. The visual 
tourism of the twentieth century recovered stories that for many were forgotten. This oblivion is characteristic of inhabiting a place and unnoticing components of the everyday scenario. Younger citizens referred to other adults to observe with them. For their part, the elders tried to specify the location of the photographed places and in their attempt they navigated stories of their childhood. The stories crossed the market spout, the Ferrans bridge, the old grain market and the so call street of the cows, among many places and events that resonate in the collective memory, such as the existence of commercial establishments known by their owners' names or the existence of registration plates for donkey carriages.

San Nicolas image for instance, continuously led to stories about the fire that occurred there in 1948 after the assassination of the presidential candidate Jorge Eliecer Gaitán. Men at Desk

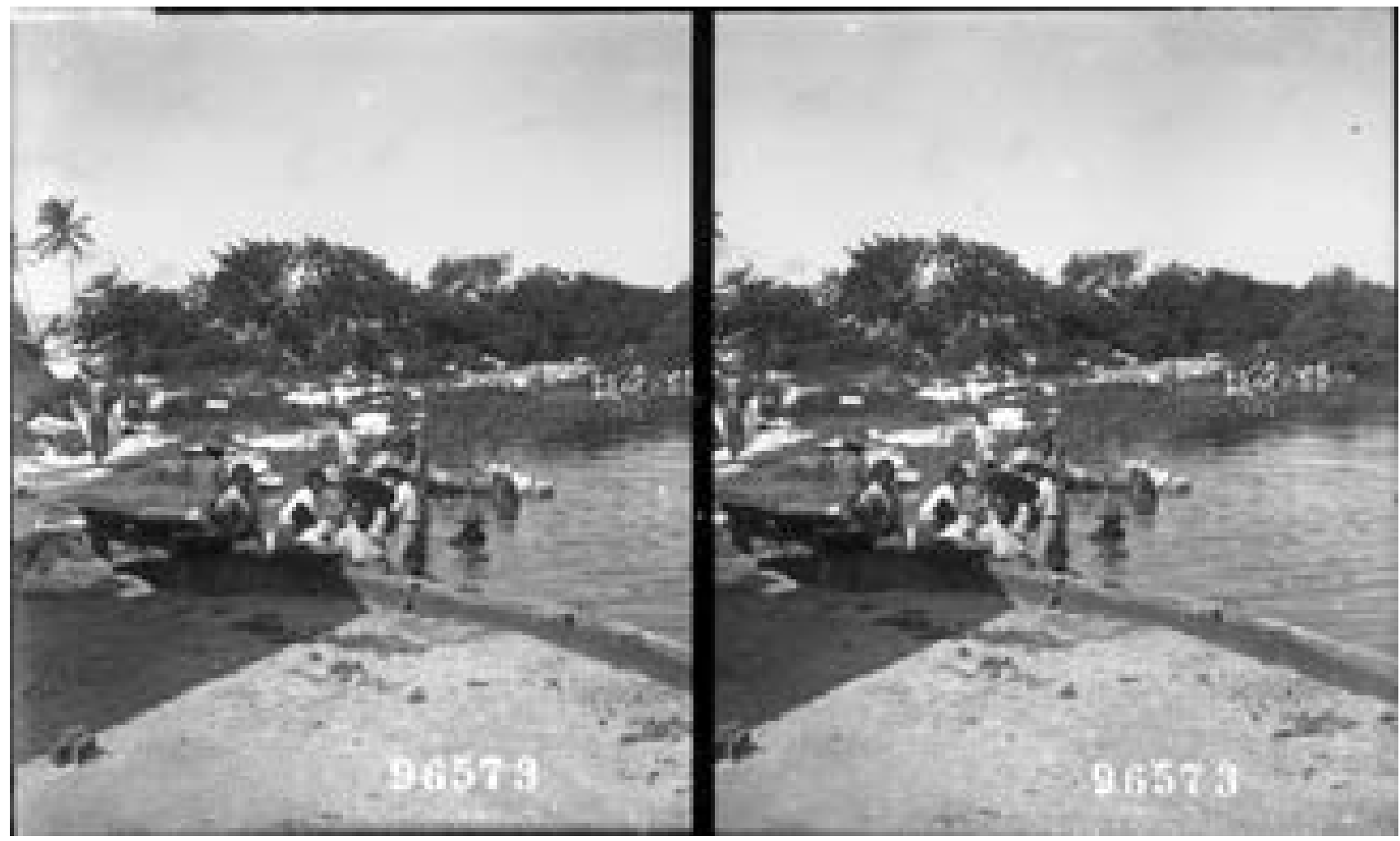

Figure 10: A Colombian Washing Day Along the Magdalena River Near Barranquilla, Colombia. Keystone Mast Collection, CR. OAC Identifier: 1996.0009.X96573

stereograph pointed to Elías Pellet, a pioneer of commercial radio in Colombia. Although the image does not match with the photos of Pellet, the stories about the radio were detonated, along with local pride of progressist Barranquilla compared to other colombian cities. In Washing day (figures 9 and 10), washerwomen and water carriers were immediately referenced. The washerwomen worked at shallow ponds near the canals and the water carriers were responsible for carrying water throughout the urban area, which also denotes memories of the trades and daily activities of their parents and children. Other washing day photographs found in the archive, werent published (figure 10), one of them, portrays a woman sitting in front of a drying clothe rope, next to a couple of younger boys who seem to rest in the shade. In different images such as the one described, under palm roofs, the descendants of mokanás were identified. This type of work was mostly performed by an ethnic group from the Atlantic that traded fish, vegetables and washed clothes in the vicinity of Barranquilla. Its culinary heritage and a petroglyph outside of Barranquilla were the only traces left from them.

For Paul Ricoeur (2010) the relation between fiction and history is assuredly more complex than we will ever be able to put into words. For the author the document poses a question that is only answer by ways of historical imagination intertwining historical facts and the observation of something present and given, as in perception. The gathered facts of the historian answer the questions that the document makes in a coherent spatial and temporal way; localizing the narrative in a historical already made world. Ricoeur understands by reading

Collingwood's The Idea of History, that the natural past dies as it pass, nonetheless the historical past "survives the present"(p. 246). Meaning that in the natural world, time is seemed as the natural 
process of death and replacement, but historical knowledge begins with the way we come into possession of it. Through the stereoscope, these documents approached the observer's closer experiences; the deceptive sensation of visual closeness triggered a reenactment of the things past. "I have seen this before!" seems to be the common reaction to the images, even though it happened years before the observers were born. As Helmholtz, observers understood the temporal gap between today and 1913, however the drive stimulated by the technique, avowed their own narrations annulling the temporal distance. In this example, visual stimuli brought the archival image closer to experience, converging circles of presentabilia anchored to past experiences of the city with blurred memories. The recognizing exercise entangles previous ideas of Barranquilla, as the most important free port in the country, a cosmopolitan city where indigenous, slaves, Europeans and creoles shared goods and space. For citizens downtown Barranquilla it seems like the survival of the past is an idea that finally could solve administration problems, and through the label of heritage and constant reenactment other citizens could understand the significance of the city center. However, for the Mokana's descendants, the stereoscope images only remind them a past passed. The stereographs do not touch them in the way they did to downtown inhabitants. Through out the interviews, they didn't seemed interested in showing the importance of their heritage to anyone, but to insure protection to the only traces of heritage they really have: land and the few natural resources left.

\section{REFERENCES}

Comolli, J. (1980) Machines of the Visible. In: T. de Lauretis and S. Heath, ed., The $C$ inematic Apparatus. 1st ed. Basingstoke: Macmillan Press, 121-142.

Comolli, J. (2010) Cine contra espectáculo seguido de técnica e ideología: 19711972. 1st ed. Buenos Aires: Manantial. 138 - 272

Crank, M. (2004) Cultural Geographies of Tourism. In: A. Lew, M. Hall and A. Williams, ed., A Companion to Tourism. 1st ed. Oxford Blackwell Publishing, 7484.

Crary, J. (2008). Las $t$ écnicas del obs ervador: visión y modernidad en el s iglo $X I X$. 1st ed translated by F. López. Murcia: Cendeac.

González Cueto, D. (2004). Una memoria visual para el futuro: La situación de los archivos fotográficos en el Caribe Colombiano. Memorias. Revista Digital de $H$ istoria y A rqueología des de el $C$ aribe. Available from: http://www.redalyc.org/articulo.oa?id=85510106 (2 may 2017).

Hayles, N. K.. (2012). How We Think: Digital Media and $C$ ontemporary $T$ echnogenesis. 1st ed. University of Chicago Press.

D'Hauteserre, A. (2004). Postcolonialism, Colonialism, and Tourism. In: A. Lew, M. Hall and A. Williams, ed., A Companion to Tourism. 1st ed. Oxford Blackwell Publishing, 74-84.

Helmholtz, H. V.. (1962). Handbook of Physiological O ptics. Vol. 3. Translated by George T. Ladd. New York: Dover.

Helmholtz, H. V.. (1878). The Facts of Perception. In: R. Kahl (ed.), Selected Writings of Hermann Helmholtz. Wesleyan University Press.

Helmholtz, H. V. (1885). Recent Progress of Theory of Vision. In: H. V. Helmholtz. and E. Atkinson, ed. On Popular Lec tures of S cientific Subjects. 2nd Ed. New York. D Appleton and Company. $270-317$.

Holmes, B. (1936). A T rip $A$ round the $W$ orld Through the Telebinocular in Three D imension Pictures. Pennsylvania: Keystone View Company.

Huhtamo, E. (2006). The Pleasures of the Peephole: An Archaeological Exploration of Peep Media. In: E. Kluitenberg, ed. Book of Imaginary Media: Excavating the D ream of the Ultimate $C$ ommunication Medi um. 1st ed. Amsterdam: NAi Publishers, 74-155.

Piedrahita, H. (1987). Estereofotografías norteamericanas: un a mi rada s obre $A$ mérica Latina e $n t$ res di mensiones. 1st ed. Bogotá: Fondo Cultural Cafetero.

Ricoeur, P. (2010a) Time and Narrative, Volume 2. [Ebook] University of Chicago Press. Available from Scribd.com https://es.scribd.com/book/207912886/TimeandNarrative-Volume-3 (28 May 2019).

Ricoeur, P. (2010b) Time and Narrative, Volume 3. [Ebook] University of Chicago Press. Available from Scribd.com https://es.scribd.com/book/207912886/TimeandNarrative-Volume-3 (28 May 2019).

Shattuck, R. (2016) Proust's Binoculars: A Study of Memory, $T$ ime, an $d R$ ecognition $i \quad A l$ a recherché du temps perdu. 3rd ed. Princeton Press: New Jersey.

Silverman, K. (2009) El u mbral del mundo visible. Translated by A. Brotons. Madrid: Akal.

Thompson, K.A. (2007). An E ye for the Tropics: Tourism, $P$ hotography, and $F$ raming $t$ he Caribbean Picturesque. [Kindle] Duke University Press. Available at Amazon.com 
$<$ https://www.amazon.com/Eye-TropicsPhotography-Caribbean-Picturesque-ebook-dpB00EHNSR56/dp/B00EHNSR56/ref=mt kindle? encoding=UTF8\&me=\&qid=> [Accessed 28 May 2019].

J. Urry. (1990). The Tourist Gaze: Leisure and Travel i $n C$ ontemporary $S$ ocieties. 1st ed. London: Sage.

J. Urry. (2002). The Tourist Gaze. 2nd ed. London: Sage.

\section{VISUAL REFERENCES}

Man at desk, Panama. Keystone-Mast Collection. Online Archive of California. OAC Identifier1996.0009.X89239. http://oac.cdlib.org/ark:/13030/kt2r29p5n8/?order $=2 \&$ brand $=0 a c 4$

Man at his desk. Barranquilla, Columbia. KeystoneMast Collection. Online Archive of California. OAC Identifier 1996.0009.X96450. http://oac.cdlib.org/ark:/13030/kt1m3nb89w/?ord er=2\&brand=oac4

Man at his desk. Cuba. Keystone-Mast Collection. Online Archive of California. OAC

Identifier 1996.0009.X46160. http://oac.cdlib.org/ark:/13030/kt8000158v/?bran $\mathrm{d}=$ oac4

Mr. Jerome. District attorney at his desk. New York. Keystone-Mast Collection. Online Archive of California. OAC Identifier 1996.0009.WX13006.SS. http://oac.cdlib.org/ark:/13030/kt1g5014t6/?order $=2 \&$ brand $=0 a c 4$

Wash Day. Cuzco. Perú. Keystone-Mast Collection. Online Archive of California. OAC Identifier 1996.0009.X93152.

http://content.cdlib.org/ark:/13030/kt4580146v/?o rder=2\&brand=calisphere

Wash Day. Cuba Keystone-Mast Collection. Online Archive of California. OAC Identifier 1996.0009.X45938. http://oac.cdlib.org/ark:/13030/kt3f59p5vq/?order $=2 \&$ brand $=0$ ac 4

Filipino Wash - Day On The Banks Of The Pasig, Manila. Keystone-Mast Collection. Online Archive of California. OAC Identifier 1996.0009.V10003.

http://oac.cdlib.org/ark:/13030/kt829015nn/?orde $\mathrm{r}=2 \&$ brand $=0 \mathrm{oc} 4$

Wash Day. Pennsylvania. V. J. Stanton. KeystoneMast Collection. Online Archive of California. OAC Identifier 1996.0009.21300. http://oac.colib.org/ark:/13030/kt9b69q2vx/?orde $\mathrm{r}=2 \&$ brand $=0$ ac 4

A Colombian Washing Day - Along the Magdalena River Near Barranquilla, Columbia. S.A. Keystone-Mast Collection. Online Archive of California. OAC Identifier 1996.0009.X11517. http://oac.cdlib.org/ark:/13030/kt4k4012s9/?orde $\mathrm{r}=2 \&$ brand $=0 \mathrm{ac} 4$

A Colombian Washing Day - Along the Magdalena River Near Barranquilla, Columbia. S.A. Keystone-Mast Collection. Online Archive of California. OAC Identifier 1996.0009.X96573. http://oac.cdlib.org/ark:/13030/kt3k40129r/?order $=2 \&$ brand $=0 a c 4$

\section{NOTES}

i The idea that humans and technics have coevolved together (Hayles, 2012 p.34)

ii Possible perception of a conscious choice, decision, and intention.

iii https://opslab.jpl.nasa.gov/

iv http://www.themachinetobeanother.org/

v http://medvr.ict.usc.edu/projects/bravemind/

$\mathrm{vi}$ In this set of photographs men posing in front of the camera are not acknowledged by their name. Except in the case of the district attorney of NY known as Mr. Jerome. vii In this set of photographs, washing is a topic considered picturesque following a canon borrowed from landscape paintings. In the North American case, the topic is infantilized. The little girls are role-playing, there is no need to hand wash clothes, also there is nothing special about it geopolitically. 